Published in final edited form as:

Arthritis Care Res (Hoboken). 2019 February ; 71(2): 198-206. doi:10.1002/acr.23756.

\title{
Physical Activity and Worsening of Radiographic Findings in Persons With or at Higher Risk of Knee Osteoarthritis
}

\author{
Prakash Jayabalan, MD, PhD, Masha Kocherginsky, PhD, Alison Chang, DPT, MS, Gerald \\ W. Rouleau, MS, Kimberly L. Koloms, MS, Julia Lee, PhD, Dorothy Dunlop, PhD, Rowland \\ W. Chang, MD, MPH, and Leena Sharma, MD \\ Northwestern University Feinberg School of Medicine, Chicago, IL
}

\begin{abstract}
Objective: The benefits of physical activity among persons with or at higher risk for knee osteoarthritis are well established. However, activity levels in this population are low, in part due to concern that activity will damage the knee joint. We hypothesized that sedentary and moderatevigorous physical activity are each associated with greater risk of radiographic worsening of knee OA.

Methods: In Osteoarthritis Initiative participants with or at higher risk for knee OA enrolled in an accelerometer substudy at $48 \mathrm{~m}$ (study baseline), physical activity was measured by uniaxial accelerometer (ActiGraph GT1M). Radiographic progression was defined as any $48 \mathrm{~m}-96 \mathrm{~m} \mathrm{KL}$ grade worsening. All analyses were knee-level; we used multivariable logistic regression with GEE, adjusting for key covariates.
\end{abstract}

Results: 1206 persons [mean age 64 yrs (SD 9), 631 (52\%) women, BMI 28 (5), average daily sedentary activity 602 minutes (86), light activity 284 minutes (75), moderate-vigorous activity 20 minutes (20)] contributed 1978 knees; 267 (14\%) had KL worsening. In the multivariable model, age, sex, BMI, and pain, but neither sedentary activity (adjusted OR 0.99, 95\% CI 0.97-1.01) nor moderate-vigorous activity (adjusted OR 1.00, 95\% CI 0.91-1.09) were associated with KL worsening.

Conclusion: In persons with or at higher risk for knee OA, age, sex, BMI, and pain - but not objectively measured average daily minutes of sedentary or moderate-vigorous activity - were associated with subsequent worsening of KL grade. Whether findings differ in persons with more severe knee $\mathrm{OA}$ and/or engaged more frequently in moderate-vigorous activity should be examined in future studies.

Corresponding Author: Leena Sharma, M.D., Division of Rheumatology, Feinberg School of Medicine, Northwestern University, 240 E. Huron, M300, Chicago, IL 60611, 312-908-5597, L-Sharma@ northwestern.edu.

Disclosure:

No author received any financial support or other benefits from commercial sources for the work reported on in the manuscript, or have any other financial interests that could create a potential conflict of interest or the appearance of a conflict of interest with regard to the work. 


\section{INTRODUCTION}

The benefits of physical activity for overall health, wellness, and prevention of poor outcome in the general population and among those with chronic conditions including knee osteoarthritis (OA) are well established. There is evidence that physical activity is specifically associated with a reduced risk of subsequent function decline $(1,2)$ and disability $(3,4)$ in persons with or at higher risk for knee OA. However, the proportion of these individuals engaging in recommended levels of physical activity is very low $(5,6)$. This relates in part to concern about the possibility that physical activity will damage the knee joint (7-9).

With few exceptions $(10,11)$, longitudinal studies that evaluated the association between physical activity and worsening of radiographic knee OA have relied on self-report to quantify physical activity (12-18); self-report is vulnerable to reporting bias and imprecise recall. Accelerometry provides an objective method to quantify physical activity intensity and duration in daily-life settings. Based on an extensive literature, radiographic worsening is a long established, widely accepted, and easily interpreted means to evaluate disease worsening in the setting of knee OA.

In theory, both extremes of activity, i.e., prolonged periods spent inactive or in heavy activity, may be deleterious to joint tissues (19-22). At a cellular level, articular cartilage health, proteoglycan content, and tissue stiffness require functional loading for healthy joints (22-29). Temporary or permanent periods of immobilization may be associated with cartilage thinning (30-32). To our knowledge, no previous study has evaluated the association between sedentary behavior and radiographic worsening of knee OA, perhaps due to the inadequacy of self-report to assess sedentary behavior.

The Osteoarthritis Initiative (OAI), a comprehensive and state-of-the-art longitudinal cohort study of persons with or at higher risk for knee OA, and which incorporated objective physical activity assessment in an accelerometry substudy, is an ideal setting to evaluate these questions. The objective of our study was to examine the association between objectively measured physical activity at baseline and radiographic worsening of knee OA over a 4-year period in OAI participants with or at higher risk for knee OA, based on age, overweight, knee injury, knee surgery, family history, hand OA, or occupational risk factors (as detailed below). We hypothesized that objectively measured sedentary and moderatevigorous physical activity at baseline are each associated with greater risk of radiographic worsening of knee OA.

\section{PATIENTS AND METHODS}

\section{Sample.}

The OAI study is a prospective, observational cohort study including 4796 men and women, ages 45-79 years, with or at increased risk to develop symptomatic, radiographic knee OA, who were enrolled at one of four sites: Baltimore, Maryland; Columbus, Ohio; Pittsburgh, Pennsylvania; and Pawtucket, Rhode Island. To be eligible for the OAI, participants were required to have, at enrollment, symptomatic knee OA [defined as the presence in at least 
one knee at baseline: pain, aching, or stiffness in or around the knee on most days for at least one month during the past 12 months; and a definite tibiofemoral osteophyte, i.e., Kellgren Lawrence grade $(\mathrm{KL}) \geq 2$ ] or characteristics that placed them at increased risk for developing it symptomatic knee OA.. (knee symptoms in the past 12 months; overweight, defined using gender and age-specific cutpoints for weight; knee injury causing difficulty walking for at least a week; history of any knee surgery; family history of a total knee replacement for OA in a biological parent or sibling; Heberden's nodes; repetitive knee bending at work or outside work; or age 70-79 years). Exclusion criteria for the OAI were: rheumatoid arthritis or inflammatory arthritis; severe joint space narrowing in both knees on the baseline knee radiograph, or unilateral total knee replacement and severe joint space narrowing in the other knee; bilateral total knee replacement or plans to have bilateral knee replacement in the next 3 years; MRI contraindications; inability to fit in the scanner or in the knee coil (including men over $285 \mathrm{lbs}$ and women over $250 \mathrm{lbs}$ ); positive pregnancy test; inability to provide a blood sample; use of ambulatory aides other than a single straight cane for more than $50 \%$ of the time in ambulation; comorbid conditions that might interfere with the ability to participate in a long-term study; current participation in a double-blind randomized trial.

2679 participants enrolled in the accelerometer substudy, which began at the 48-month evaluation (baseline for our study). Exclusion criteria for the current study were $<4$ valid days of physical activity monitoring and end-stage $\mathrm{OA}$ at baseline [i.e., using alternative definitions of end-stage disease, 48-month lateral or medial joint space grade 3 or KL 4]. We used follow-up data through the 96-month study visit. The Institutional Review Board at each site approved the study.

\section{Physical Activity.}

Trained OAI research personnel gave scripted in-person instructions on how to wear an ActiGraph GT1M accelerometer for seven consecutive days on a belt at the natural waistline on the right hip in line with the right axilla from arising in the morning until retiring, except during water activities. Accelerometer output is an activity count, which is the weighted sum of the accelerations measured over a minute, where the weights are proportional to the magnitude of acceleration. Non-wear periods were defined as $\geq 90$ minutes with zero activity counts (allowing for two consecutive interrupted minutes with counts $\leq 100$ ). We included participants with $\geq 4$ valid monitoring days, defined as $\geq 10$ wear hours per day, as required for reliable estimates of physical activity (33). Intensity thresholds on a minute-byminute basis used by the National Cancer Institute developed by Troiano et al. were applied to identify sedentary (0-99 counts/minute), light intensity (100 scounts/minute < 2020) and moderate to vigorous intensity (counts/minute 22020 ) activity (33). Average daily minutes spent in sedentary or moderate-vigorous intensity activity were used in primary analyses.

\section{Outcome.}

Worsening was defined as any increase in KL grade between 48 months and 96 months, i.e., either by 72 months or by 96 months. To acquire knee x-rays in the OAI, the posteroanterior fixed-flexion weight-bearing protocol $(34,35)$ with a SynaFlexer ${ }^{\mathrm{TM}}$ frame was used. In centralized readings at Boston University, two experts (36), blinded to the other's reading, 
hypotheses, and all other data, assessed KL grade (37). Adjudication included a third reader for disagreements on: $\mathrm{KL} \geq 2$ vs. $\mathrm{KL}<2$ at any timepoint; and between any timepoints, change in $\mathrm{KL}$ (36). It is widely accepted that knee OA begins before the radiographic definition of knee $\mathrm{OA}(\mathrm{KL} \geq 2)$, but when a high-risk state becomes disease is not clear. By including all knees that could worsen (i.e., KL < 4), we capitalized on the strength of the OAI in capturing the full spectrum of baseline disease severity, not one that is truncated at $\mathrm{KL}=2$.

\section{Covariates.}

Body weight was measured in the OAI using a standard balance beam scale, in lightweight clothes, without shoes or heavy jewelry, and with pockets emptied (http://oai.epi-ucsf.org/ datarelease/operationsManuals/WeightV1_0p.pdf). Height was measured using a wallmounted stadiometer, barefoot or wearing thin stockings or socks (http://oai.epi-ucsf.org/ datarelease/operationsManuals/HeightV1_0p.pdf). BMI was calculated as the weight in $\mathrm{kg}$ divided by the height in meters squared. Race was assessed by self-report and analyzed as non-white vs. white (reference group). Knee pain was assessed using the Western Ontario and McMaster Universities Osteoarthritis Index (WOMAC) Pain scale (38), adapted by the OAI to score pain separately for each knee. Knee injury was defined as ever injured either knee badly enough to limit ability to walk for at least 2 days, prior to study baseline vs. no injury (reference group). Knee surgery was defined as any knee surgery or arthroscopy prior to study baseline vs. no surgery (reference group). In the OAI, standing bilateral full-limb radiographs were acquired either at $12 \mathrm{~m}$ or $24 \mathrm{~m}$ (35), The hip-knee-ankle angle (i.e., variable HKANGJD) was calculated from 3 landmarks (39), as the angle subtended between the line through the femoral head and knee centers and the line through knee and tibiotalar joint centers, with varus as negative and valgus positive (39).

\section{Statistical Analysis.}

Person-level and knee-level variables were summarized using descriptive statistics. Personlevel continuous variables were compared between groups using a two-sample t-test, and categorical variables were compared using the chi-squared test. Continuous knee-level variables were compared between groups using a random effects model with person as the random effect, and categorical variables were compared using the Cochran-Mantel-Haenszel test. Correlation between average daily activity counts spent in sedentary or moderatevigorous activity type was assessed using Pearson's correlation coefficient (r). Multivariable generalized estimating equations (GEE) logistic regression models were used to examine the effect of physical activity at baseline on subsequent progression, adjusting for other baseline demographic and clinical characteristics. The outcome variable of radiographic knee OA worsening was defined as an increase of at least one KL grade at either the 72 or the 96month visit. GEE models account for the within-subject correlation between knees, and use all available person-level and knee-level data. Three types of models were fitted: Model 1 included only key baseline variables (age, sex, and BMI); Model 2 examined the effect of sedentary and moderate-vigorous activity adjusted for covariates in Model 1 and average daily wear time; and Model 3 additionally adjusted for race and potential confounders, knee injury, knee surgery, and WOMAC Pain. Linearity constraints and the need to control for wear time precluded the further addition of light activity into these models. These three 
models were fitted in order to first obtain the estimated effects of the usual risk factors on radiographic worsening in the study sample (Model 1), as well as estimated effects of the different physical activity types adjusted for these factors (Model 2) and both demographic and clinical (Model 3) factors. Odds ratios (ORs) and their associated 95\% confidence intervals (CIs) are presented for each of these models. Analyses were performed using SAS software, version 9.4 (Cary, NC).

\section{RESULTS}

Figure 1 depicts derivation of the analysis sample. The sample included 1206 persons who contributed 1978 knees (described in Table 1). The main reason for study exclusion among $\mathrm{n}$ $=2679$ accelerometry sub-study participants was having < 4 valid days of physical activity monitoring and missing one more of the radiographic assessments. Persons who were eligible for the accelerometer study and had knees at risk for worsening but were excluded from the study $(\mathrm{n}=1473)$ were older, had a greater proportion of women and AfricanAmericans, had higher BMI and a higher rate of prior surgery. The rate of prior knee injury was similar between these groups. Baseline knee-level characteristics of these persons included greater pain, higher KL-grade disease, and fewer knees with neutral alignment.

Average wear time in the study sample was 14.9 hours per day (SD 1.3). Consistent with other studies, the majority of time was spent in sedentary activity, followed by light activity and little moderate-vigorous [20.0 $(\mathrm{SD}=20)$ minutes per day] activity. Distributions of average daily minutes spent in sedentary, light, and moderate-vigorous activity are depicted for the full study sample in Figure 2, and was similar between men and women (Figure 3). Correlation between sedentary and moderate-vigorous activity was low $(r=-0.13)$.

Radiographic worsening was observed in 267 (14.0\%) of 1978 knees. Results from GEE logistic regression models with different sets of predictors are presented in Table 2. Age, sex (female) and BMI were significantly associated with OA worsening (Model 1). Neither sedentary $(\mathrm{p}=0.17)$ nor moderate-vigorous $(\mathrm{p}=0.63)$ activity time at baseline was associated with OA worsening when adjusting for age, gender, BMI, and wear time (Model 2) and when additionally adjusting for knee injury, knee surgery, and WOMAC Pain (Model 3). We repeated these models in secondary analyses including knees with radiographic OA $(\mathrm{KL} \geq 2)$ at baseline; neither sedentary (adjusted OR 1.03, 95\% CI 0.98, 1.08) nor moderatevigorous (adjusted OR $0.84,95 \%$ CI $0.67,1.07$ ) activity at baseline was associated with OA worsening, adjusting for age, gender, BMI, wear time, knee injury, knee surgery, and WOMAC Pain.

In sensitivity analyses using the Freedson cut-points for activity intensity, findings were similar. We also considered whether there was an interaction between sex and time spent at each activity level in Model 3. The interaction was not statistically significant for sedentary activity. For moderate-vigorous activity, the interaction was marginally statistically significant ( $\mathrm{p}=0.046$ ), but the estimated odds ratios for OA worsening per 10 minutes increase in moderate-vigorous activity were not statistically significant among women (OR $=1.07 ; \mathrm{p}=0.21)$ or among men $(\mathrm{OR}=0.93 ; \mathrm{p}=0.21)$. Interactions between $\mathrm{KL}$ grade at 
baseline and time spent in sedentary or moderate-vigorous activity were not significant when added to Model 3.

\section{DISCUSSION}

In persons with or at higher risk for knee OA, age, sex, BMI, and pain - but not objectively assessed average daily minutes of sedentary or moderate-vigorous intensity physical activity - were associated with subsequent worsening of radiographic knee OA. There is abundant evidence of the health benefits of reducing sedentary time and increasing physical activity; our findings do not reveal any evidence that physical activity, at least as engaged in by the study participants, is detrimental to joint structure.

Our findings are in keeping with previous longitudinal studies of self-reported physical activity and radiographic outcome. Particularly significant among these is the Framingham study, in which habitual physical activity (hours at various levels of activity) uniquely assessed at two time points, did not predict knee OA (12). A case-control study of persons aged 55 years and older revealed no association between knee OA and lifetime leisure activities including walking, cycling, gardening, dancing, and outdoor sports (13). In a longitudinal study of the Chingford cohort, physical activity, assessed at baseline in categories of walking, job, and sport, was not linked to incident knee OA (14). MOST (Multicenter Osteoarthritis) Study and OAI participants at higher risk for knee OA who were in the highest quartile of physical activity (assessed at baseline by the Physical Activity Scale for the Elderly) by sex were not at higher risk for developing radiographic knee OA (15). Meeting Department of Health and Human Services physical activity guidelines was not associated with incident knee OA in middle-aged or older adults in the Johnston County Osteoarthritis Project (16).

Our findings are in keeping with the few previous studies which utilized objective measures of physical activity. In the MOST Study, in persons at higher risk or with mild OA, there was no association between daily walking, measured objectively using a StepWatch or with time spent walking at a moderate to vigorous intensity at the 60-month visit and radiographic progression by the 84-month visit (10). In OAI participants at higher risk of knee OA but free of the outcome of interest, $\geq 150$ minutes per week of moderate-vigorous physical activity was not associated with incident radiographic knee OA, symptomatic knee OA or joint space narrowing vs. $<10$ minutes of moderate-vigorous activity per week (11). Longitudinal studies using MRI-based outcomes have also mostly relied on self-reported physical activity (40-44), with some exceptions $(10,45)$; these studies have had mixed results.

It is believed that articular or peri-articular abnormalities in knees without OA may increase the physical activity-associated risk of incident OA, and that abnormalities due to OA itself may increase the activity-associated risk of disease progression. As in our study, in the studies described above, it is likely that most participants were not involved in heavy activity. Previous studies that have sought to specifically examine heavy activity have had somewhat mixed results. In the Framingham study, involvement in more than 4 hours per day of heavy physical activity assessed at mid-study was associated with increased odds of 
developing knee OA between two exams eight years apart; the greatest risk was in the top BMI tertile (17). Moderate or light physical activity, number of blocks walked, or number of flights of stairs climbed daily were not associated with increased risk. In contrast, a subsequent study showed neither recreational walking, jogging, frequent working up a sweat, nor high activity levels relative to peers by self-report at baseline altered the risk of knee OA or joint space loss, even in persons with higher BMI (18).

Our findings are reassuring but uncertainty remains. Because our study required longitudinal radiographic readings, the sample of the current study only included $63.4 \%$ of the accelerometry study sample with 4-7 days of valid monitoring. Comparison of attributes of the study sample with persons and knees who were eligible but were not included revealed small but potentially important differences in BMI (higher), race (higher proportion AfricanAmerican), previous knee surgery (more frequent), light activity (lower), and moderatevigorous activity (lower), pain (greater), disease severity (worse), and malalignment (worse). Reasons for exclusion were a large number of missing baseline radiographic assessments, which made it impossible to assess radiographic progression. Since it is impossible to know what impact the inclusion of these individuals would have had on our findings, we cannot make definitive conclusions regarding effects of either sedentary or moderate-vigorous activity. The current study has additional limitations. The vast majority of knees in our analysis sample had mild OA at baseline and time spent in moderate-vigorous activity was relatively low; vigorous activity was too infrequent to separately analyze Whether findings differ in persons with more severe knee OA and/or engaged more frequently in moderate or vigorous activity should be examined in future studies. Physical activity was only measured at baseline; due to the likely decline in activity over the four year study period among these older adults, this baseline analysis is conservative, i.e., potentially overestimating the relationship of physical activity to worsening. Although widely used and inexpensive, radiography has inherent weaknesses. Given the decades-long trajectory of knee OA, our follow-up period of up to 4 years was relatively short. As is an inherent issue with largescale studies, not all participants remained in the study through the 96 month visit. Out of 1978 knees, 1831 (92.6\%) had no missing assessments (i.e., had 48, 72, and 96 months), 69/1978 (3.5\%) knees had missing 72 month assessment only, and 76/1978 (3.8\%) had missing 96 month assessment only. Because the number of missing knees is similar at 72 and 96 months, it is likely to be missing at random, as opposed to a systematic pattern of higher missingness later in the study. In addition, because the overall proportion of knees with missing assessments is very low, we do not expect this to have an impact on our findings.

Nevertheless, it is important to present these findings. While the OAI accelerometer substudy was designed to examine function and disability outcomes, the comprehensive data collection in the OAI afforded an excellent opportunity to explore the association between objectively measured physical activity and worsening of radiographic features of knee OA. To our knowledge, this substudy represents the largest accelerometry study in persons with or at higher risk for knee OA and the best opportunity that currently exists to examine these questions. It is notable that many previous studies and the current study focused on persons without or at mild stages of knee OA. Less is known about the impact of physical activity in persons with moderately severe knee OA. The ideal study, i.e., including a more balanced 
representation of various stages of knee OA disease severity along with more frequent moderate-vigorous activity, may not be realizable, particularly given the relative inactivity of this population. This inactivity is likely to be multifactorial, but relates in part to concerns about potential adverse effects of physical activity on the knee joint itself (7-9). A largescale pragmatic design may be better, although would have to adapt methods to objectively measure physical activity and knee joint structure to meet this scale.

In conclusion, in a subset of OAI participants with or at higher risk for knee OA, there was no association between objectively measured moderate-vigorous physical activity at baseline and worsening of radiographic knee OA over up to 4 years of follow-up.

\title{
ACKNOWLEDGEMENTS
}

\begin{abstract}
We would like to acknowledge the dedication and commitment of the OAI study participants. The OAI is a publicprivate partnership comprised of five contracts (N01-AR-2-2258; N01-AR-2-2259; N01-AR-2-2260; N01-AR-22261; N01-AR-2-2262) funded by the NIH and conducted by the OAI Study Investigators. Private funding partners include Merck Research Laboratories, Novartis Pharmaceuticals Corporation, GlaxoSmithKline, and Pfizer, Inc. Private sector funding for the OAI is managed by the Foundation for the NIH. This manuscript was prepared using an OAI public use data set and does not necessarily reflect the opinions or views of the OAI investigators, the NIH, or the private funding partners.
\end{abstract}

Funding: NIH/NIAMS 2R01AR054155-05, R01AR065473, P60AR064464, P30AR072579, NUCATS UL1TR001422, and the Osteoarthritis Initiative. The study sponsors played no role in study design, collection, analysis, or interpretation of data, writing of the manuscript, or the decision to submit the manuscript for publication.

\section{REFERENCES}

1. Dunlop DD, Song J, Semanik PA, Sharma L, Chang RW. Physical activity levels and functional performance in the osteoarthritis initiative: a graded relationship. Arthritis Rheum. 2011;63(1):12736. [PubMed: 20862681]

2. Dunlop DD, Song J, Lee J, Gilbert AL, Semanik PA, Ehrlich-Jones L, et al. Physical Activity Minimum Threshold Predicting Improved Function in Adults With Lower-Extremity Symptoms. Arthritis Care Res (Hoboken). 2017;69(4):475-83. [PubMed: 28029748]

3. Dunlop DD, Song J, Semanik PA, Sharma L, Bathon JM, Eaton CB, et al. Relation of physical activity time to incident disability in community dwelling adults with or at risk of knee arthritis: prospective cohort study. BMJ. 2014;348:g2472. [PubMed: 24782514]

4. Song J, Gilbert AL, Chang RW, Pellegrini CA, Ehrlich-Jones LS, Lee J, et al. Do Inactive Older Adults Who Increase Physical Activity Experience Less Disability: Evidence From the Osteoarthritis Initiative. J Clin Rheumatol. 2017;23(1):26-32. [PubMed: 28002153]

5. Dunlop DD, Song J, Semanik PA, Chang RW, Sharma L, Bathon JM, et al. Objective physical activity measurement in the osteoarthritis initiative: Are guidelines being met? Arthritis Rheum. 2011;63(11):3372-82. [PubMed: 21792835]

6. Murphy LB, Hootman JM, Boring MA, Carlson SA, Qin J, Barbour KE, et al. Leisure Time Physical Activity Among U.S. Adults With Arthritis, 2008-2015. Am J Prev Med. 2017;53(3):34554. [PubMed: 28601405]

7. Holden MA, Nicholls EE, Young J, Hay EM, Foster NE. Role of exercise for knee pain: what do older adults in the community think? Arthritis Care Res (Hoboken). 2012;64(10):1554-64. [PubMed: 22511582]

8. Wilcox S, Der Ananian C, Abbott J, Vrazel J, Ramsey C, Sharpe PA, et al. Perceived exercise barriers, enablers, and benefits among exercising and nonexercising adults with arthritis: results from a qualitative study. Arthritis Rheum. 2006;55(4):616-27. [PubMed: 16874785] 
9. Stone RC, Baker J. Painful Choices: A Qualitative Exploration of Facilitators and Barriers to Active Lifestyles Among Adults With Osteoarthritis. J Appl Gerontol. 2017;36(9):1091-116. [PubMed: 26316267]

10. Oiestad BE, Quinn E, White D, Roemer F, Guermazi A, Nevitt M, et al. No Association between Daily Walking and Knee Structural Changes in People at Risk of or with Mild Knee Osteoarthritis. Prospective Data from the Multicenter Osteoarthritis Study. J Rheumatol. 2015;42(9):1685-93. [PubMed: 26077404]

11. Qin J, Barbour KE, Nevitt MC, Helmick CG, Hootman JM, Murphy LB, et al. Objectively Measured Physical Activity and Risk of Knee Osteoarthritis. Med Sci Sports Exerc. 2018;50(2): 277-83. [PubMed: 28976494]

12. Hannan MT, Felson DT, Anderson JJ, Naimark A. Habitual physical activity is not associated with knee osteoarthritis: the Framingham Study. J Rheumatol. 1993;20(4):704-9. [PubMed: 8496869]

13. Cooper C, Snow S, McAlindon TE, Kellingray S, Stuart B, Coggon D, et al. Risk factors for the incidence and progression of radiographic knee osteoarthritis. Arthritis Rheum. 2000;43(5):9951000. [PubMed: 10817551]

14. Hart DJ, Doyle DV, Spector TD. Incidence and risk factors for radiographic knee osteoarthritis in middle-aged women: the Chingford Study. Arthritis Rheum. 1999;42(1):17-24. [PubMed: 9920009]

15. Felson DT, Niu J, Yang T, Torner J, Lewis CE, Aliabadi P, et al. Physical activity, alignment and knee osteoarthritis: data from MOST and the OAI. Osteoarthritis Cartilage. 2013;21(6):789-95. [PubMed: 23523851]

16. Barbour KE, Hootman JM, Helmick CG, Murphy LB, Theis KA, Schwartz TA, et al. Meeting physical activity guidelines and the risk of incident knee osteoarthritis: a population-based prospective cohort study. Arthritis Care Res (Hoboken). 2014;66(1):139-46. [PubMed: 23983187]

17. McAlindon TE, Wilson PW, Aliabadi P, Weissman B, Felson DT. Level of physical activity and the risk of radiographic and symptomatic knee osteoarthritis in the elderly: the Framingham study. Am J Med. 1999;106(2):151-7. [PubMed: 10230743]

18. Felson DT, Niu J, Clancy M, Sack B, Aliabadi P, Zhang Y. Effect of recreational physical activities on the development of knee osteoarthritis in older adults of different weights: the Framingham Study. Arthritis Rheum. 2007;57(1):6-12. [PubMed: 17266077]

19. Bader DL, Salter DM, Chowdhury TT. Biomechanical influence of cartilage homeostasis in health and disease. Arthritis. 2011;2011:979032. [PubMed: 22046527]

20. Arokoski JP, Jurvelin JS, Vaatainen U, Helminen HJ. Normal and pathological adaptations of articular cartilage to joint loading. Scand J Med Sci Sports. 2000;10(4):186-98. [PubMed: 10898262]

21. Eckstein F, Hudelmaier M, Putz R. The effects of exercise on human articular cartilage. J Anat. 2006;208(4):491-512. [PubMed: 16637874]

22. Salter DM, Aigner T. Pathogenesis and pathology of osteoarthritis In: Hochberg M, Gravallese EM, Silman AJ, Smolen JS, Weinblatt ME, Weisman MH, eds. Rheumatology. 7th ed. Philadelphia PA: Elsevier; 2019:1537-49.

23. Nomura M, Sakitani N, Iwasawa H, Kohara Y, Takano S, Wakimoto Y, et al. Thinning of articular cartilage after joint unloading or immobilization. An experimental investigation of the pathogenesis in mice. Osteoarthritis Cartilage. 2017;25(5):727-36. [PubMed: 27916560]

24. Hinterwimmer S, Krammer M, Krotz M, Glaser C, Baumgart R, Reiser M, et al. Cartilage atrophy in the knees of patients after seven weeks of partial load bearing. Arthritis Rheum. 2004;50(8): 2516-20. [PubMed: 15334465]

25. Vanwanseele B, Eckstein F, Knecht H, Spaepen A, Stussi E. Longitudinal analysis of cartilage atrophy in the knees of patients with spinal cord injury. Arthritis Rheum. 2003;48(12):3377-81. [PubMed: 14673989]

26. Haapala J, Arokoski J, Pirttimaki J, Lyyra T, Jurvelin J, Tammi M, et al. Incomplete restoration of immobilization induced softening of young beagle knee articular cartilage after 50-week remobilization. Int J Sports Med. 2000;21(1):76-81. [PubMed: 10683104] 
27. Vanwanseele B, Lucchinetti E, Stussi E. The effects of immobilization on the characteristics of articular cartilage: current concepts and future directions. Osteoarthritis Cartilage. 2002;10(5): 408-19. [PubMed: 12027542]

28. Jurvelin J, Kiviranta I, Tammi M, Helminen JH. Softening of canine articular cartilage after immobilization of the knee joint. Clin Orthop Relat Res. 1986(207):246-52.

29. Jortikka MO, Inkinen RI, Tammi MI, Parkkinen JJ, Haapala J, Kiviranta I, et al. Immobilisation causes longlasting matrix changes both in the immobilised and contralateral joint cartilage. Ann Rheum Dis. 1997;56(4):255-61. [PubMed: 9165998]

30. Hinterwimmer S, Krammer M, Krötz M, Glaser C, Baumgart R, Reiser M, et al. Cartilage atrophy in the knees of patients after seven weeks of partial load bearing. Arthritis and Rheumatism. 2004;50(8):2516-20. [PubMed: 15334465]

31. Vanwanseele, Eckstein F, Knecht H, Stüssi E, Spaepen A. Knee cartilage of spinal cord-injured patients displays progressive thinning in the absence of normal joint loading and movement. Arthritis and Rheumatism. 2002;46(8):2073-8. [PubMed: 12209511]

32. Vanwanseele B, Eckstein F, Knecht H, Spaepen A, Stüssis E. Longitudinal Analysis of Cartilage Atrophy in the Knees of Patients with Spinal Cord Injury. Arthritis and Rheumatism. 2003;48(12): 3377-81. [PubMed: 14673989]

33. Troiano RP, Berrigan D, Dodd KW, Masse LC, Tilert T, McDowell M. Physical activity in the United States measured by accelerometer. Med Sci Sports Exerc. 2008;40(1):181-8. [PubMed: 18091006]

34. Nevitt MC, Felson D, Lester G;Pages on 5272015.

35. Bowen ME. The relationship between body weight, frailty, and the disablement process. Journals of Gerontology Series B: Psychological Sciences and Social Sciences. 2012;67(5):618-26.

36. Lee JS, Kritchevsky SB, Tylavsky F, Harris T, Simonsick EM, Rubin SM, et al. Weight change, weight change intention, and the incidence of mobility limitation in well-functioning communitydwelling older adults. The Journals of Gerontology Series A: Biological Sciences and Medical Sciences. 2005;60(8):1007-12.

37. Kellgren JH, Lawrence JS. Radiological assessment of osteo-arthrosis. Ann Rheum Dis. 1957;16(4):494-502. [PubMed: 13498604]

38. Bellamy N, Buchanan WW, Goldsmith CH, Campbell J, Stitt LW. Validation study of WOMAC: a health status instrument for measuring clinically important patient relevant outcomes to antirheumatic drug therapy in patients with osteoarthritis of the hip or knee. The Journal of rheumatology. 1988;15(12):1833-40. [PubMed: 3068365]

39. Christensen R, Bartels EM, Astrup A, Bliddal H. Effect of weight reduction in obese patients diagnosed with knee osteoarthritis: a systematic review and meta-analysis. Annals of the rheumatic diseases. 2007;66(4):433-9. [PubMed: 17204567]

40. Teichtahl AJ, Wang Y, Heritier S, Wluka AE, Strauss BJ, Proietto J, et al. The interaction between physical activity and amount of baseline knee cartilage. Rheumatology (Oxford). 2016;55(7): 1277-84. [PubMed: 27032425]

41. Teichtahl AJ, Wluka AE, Forbes A, Wang Y, English DR, Giles GG, et al. Longitudinal effect of vigorous physical activity on patella cartilage morphology in people without clinical knee disease. Arthritis Rheum. 2009;61(8):1095-102. [PubMed: 19644895]

42. Teichtahl AJ, Wluka AE, Wang Y, Forbes A, Davies-Tuck ML, English DR, et al. Effect of longterm vigorous physical activity on healthy adult knee cartilage. Med Sci Sports Exerc. 2012;44(6): 985-92. [PubMed: 22215179]

43. Kwee RM, Wirth W, Hafezi-Nejad N, Zikria BA, Guermazi A, Demehri S. Role of physical activity in cartilage damage progression of subjects with baseline full-thickness cartilage defects in medial tibiofemoral compartment: data from the Osteoarthritis Initiative. Osteoarthritis Cartilage. 2016;24(11):1898-904. [PubMed: 27327782]

44. Lin W, Alizai H, Joseph GB, Srikhum W, Nevitt MC, Lynch JA, et al. Physical activity in relation to knee cartilage T2 progression measured with $3 \mathrm{~T}$ MRI over a period of 4 years: data from the Osteoarthritis Initiative. Osteoarthritis Cartilage. 2013;21(10):1558-66. [PubMed: 23831632] 
45. Dore DA, Winzenberg TM, Ding C, Otahal P, Pelletier JP, Martel-Pelletier J, et al. The association between objectively measured physical activity and knee structural change using MRI. Ann Rheum Dis. 2013;72(7):1170-5. [PubMed: 22896739] 


\section{SIGNIFICANCE AND INNOVATIONS}

- Among persons at higher risk of with knee osteoarthritis, the proportion engaging in recommended levels of physical activity is low, in part due to concern that such activity will damage the knee. The literature concerning physical activity and worsening of knee OA disease features is limited by reliance, in the preponderance of studies, on self-report of activity, which is vulnerable to reporting bias and imprecise recall. The study described in the current report is the largest accelerometry study in this population to date and represents the best current opportunity to address these questions.

- $\quad$ Accelerometry provides an objective and valid means to assess both potentially deleterious extremes of activity intensity, i.e., sedentary activity and moderate-vigorous activity. To our knowledge, this is the first report of an investigation of the association between sedentary activity and structural outcome (by x-ray or MRI).

- $\quad$ The current study uniquely examines physical activity objectively assessed using accelerometry including knees at all baseline stages of disease; the sole prior report (to our knowledge) concerning accelerometer-assessed physical activity and disease outcome (x-ray or MRI) examined incident OA only (citation 28). 


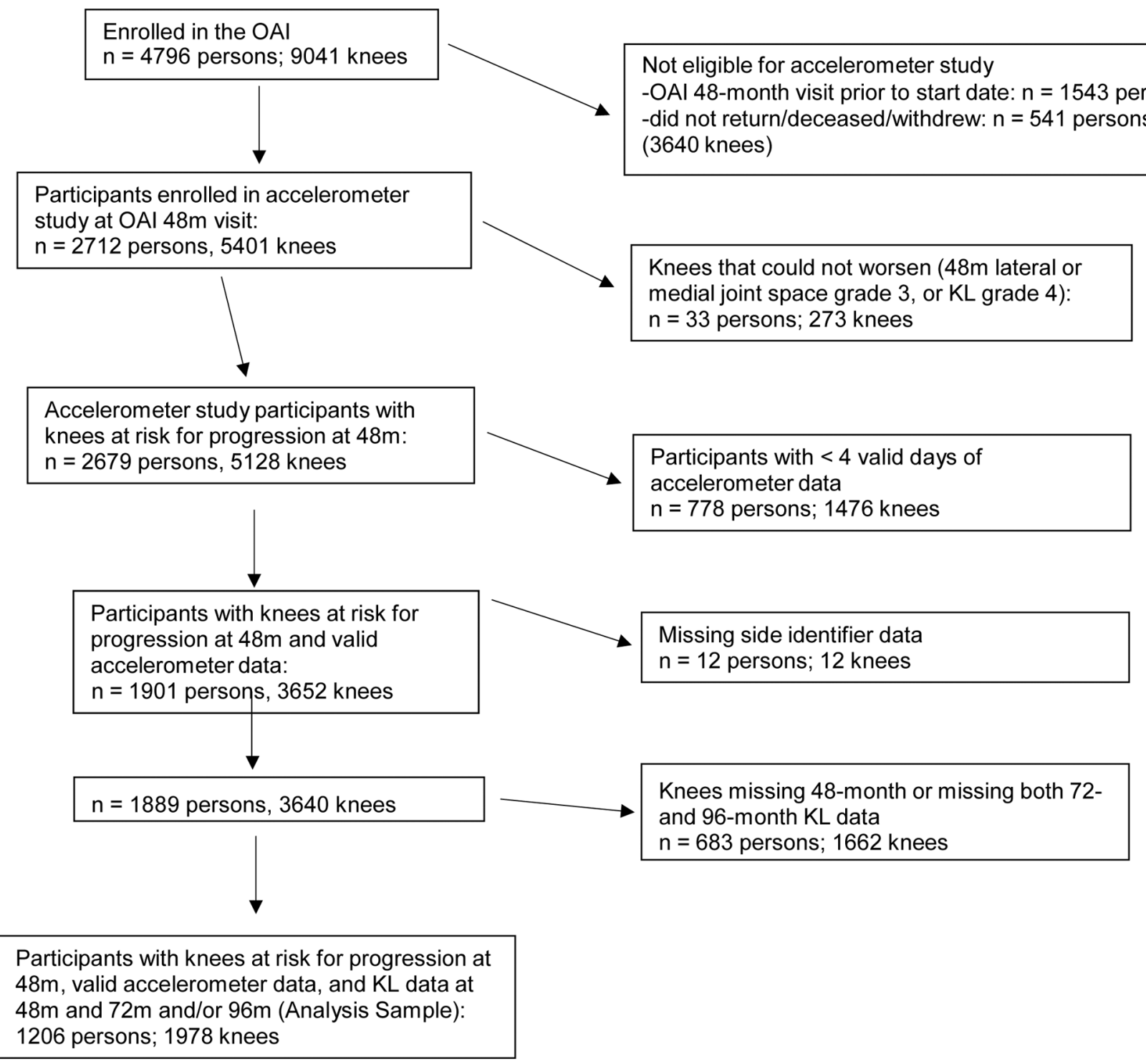

FIGURE 1.

Derivation of Analysis Sample 


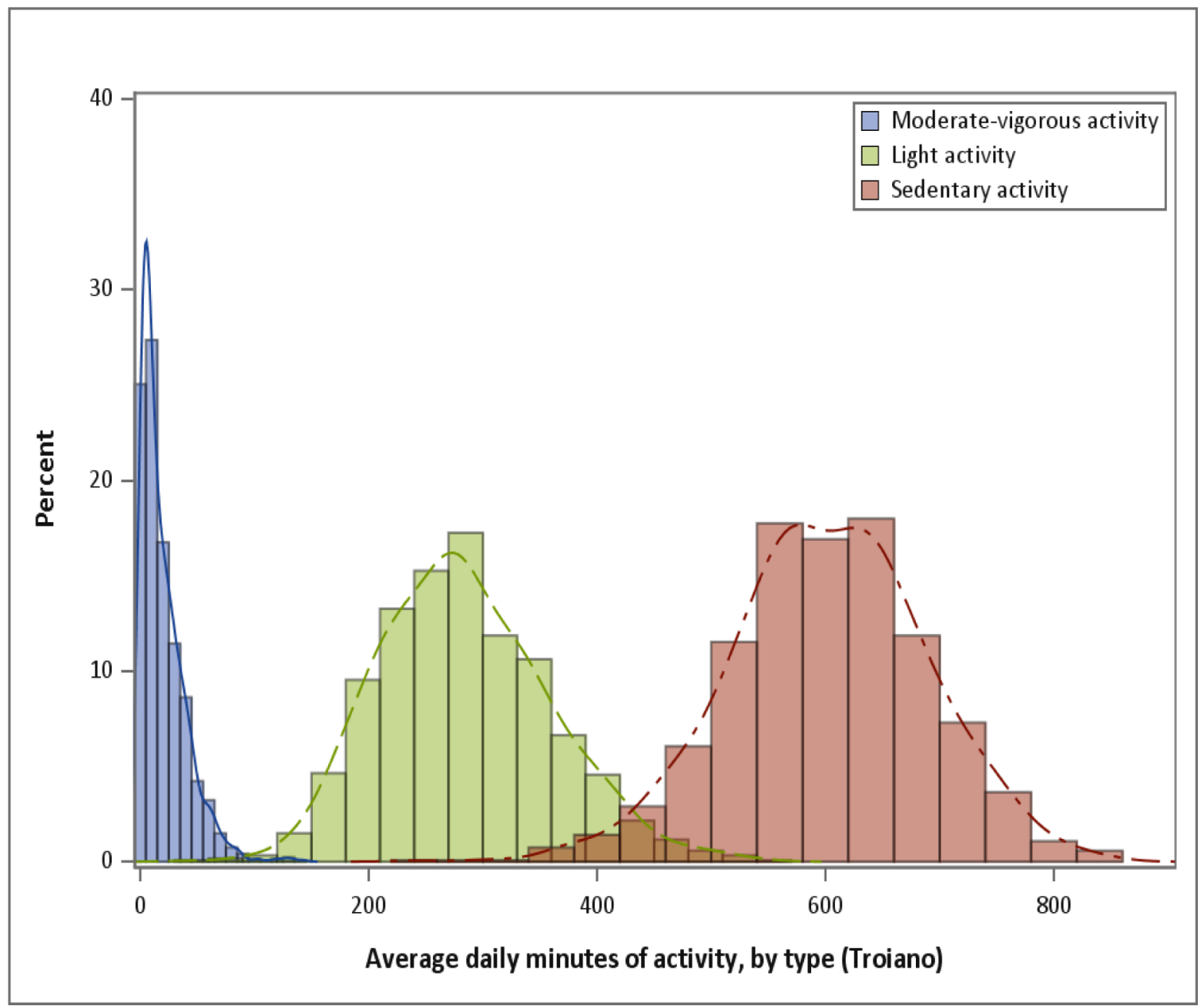

FIGURE 2.

Distribution of Average Daily Minutes of Physical Activity 
Figure $3 \mathrm{~A}$. Distribution of average daily minutes sedentary activity, by sex

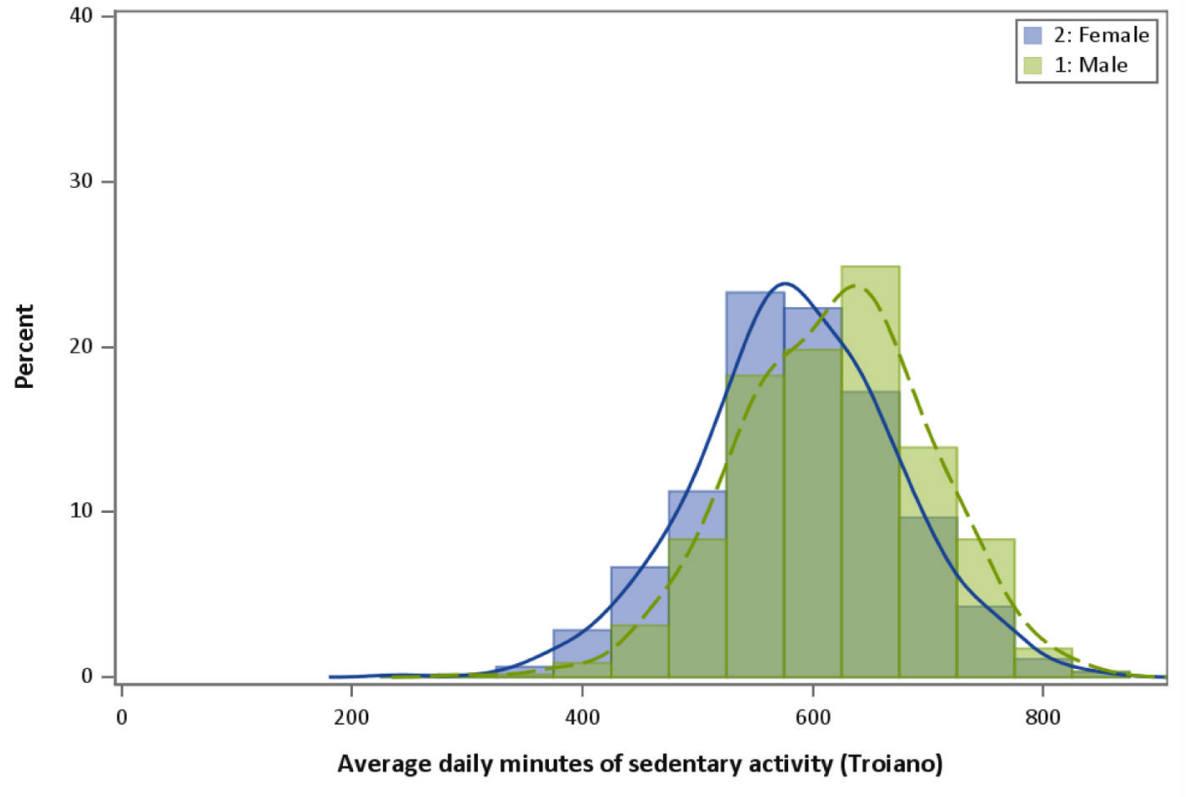

Figure 3B. Distribution of average daily minutes moderate-vigorous activity, by sex

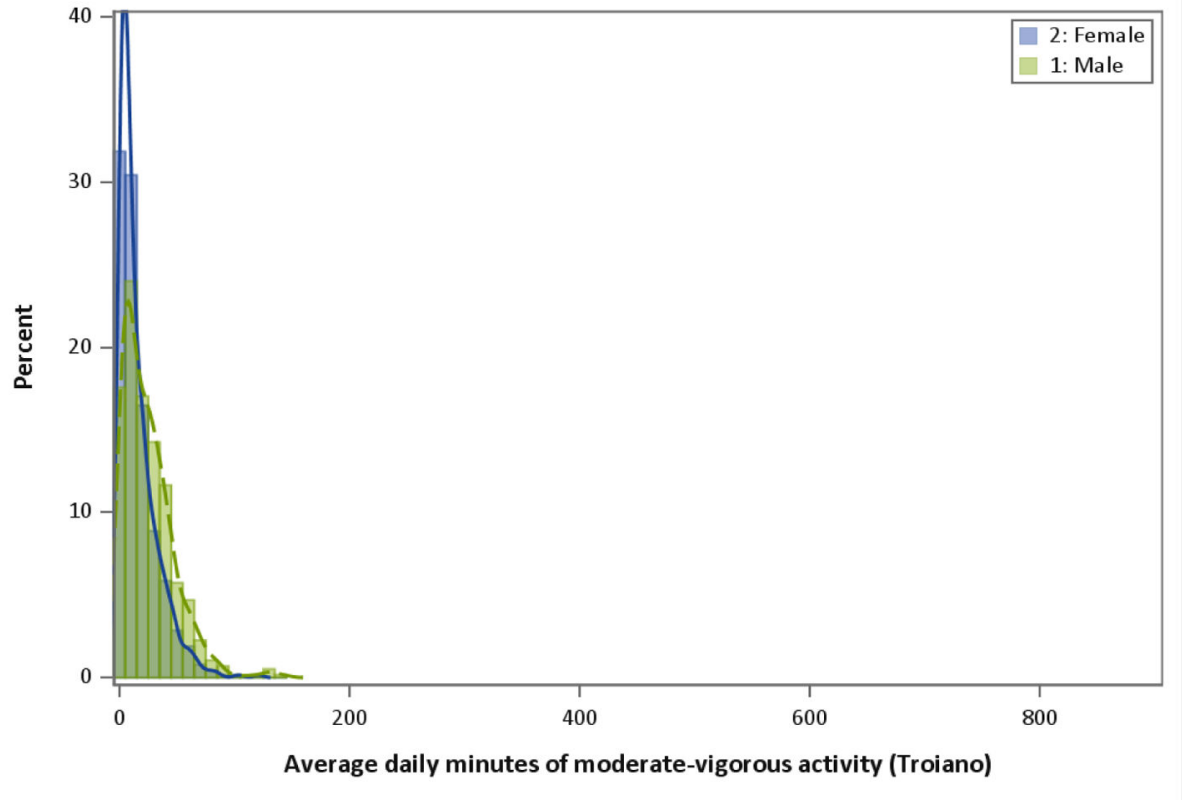

FIGURE 3.

Distribution of Average Daily Minutes of Sedentary and Moderate-Vigorous Activity, by Sex 
Table 1.

Characteristics at Study Baseline

\begin{tabular}{|c|c|c|c|}
\hline PERSON-LEVEL CHARACTERISTICS & $\begin{array}{c}\text { Included } \\
\mathrm{n}=\mathbf{1 2 0 6} \text { persons }\end{array}$ & $\begin{array}{c}\quad \text { Excluded } \\
\mathrm{n}=\mathbf{1 4 7 3} \text { persons }\end{array}$ & p-value ${ }^{*}$ \\
\hline Age, mean (SD) & $64.1(9.0)$ & $66.1(9.2)$ & $<0.001$ \\
\hline \multicolumn{4}{|l|}{ Age group, $\mathrm{n}(\%)$} \\
\hline $45-54$ & $195(16.1 \%)$ & $181(12.3 \%)$ & \multirow{4}{*}{$<0.001$} \\
\hline $55-64$ & $455(37.7 \%)$ & $474(32.2 \%)$ & \\
\hline $65-74$ & $349(28.9 \%)$ & $482(32.7 \%)$ & \\
\hline $75+$ & $207(17.2 \%)$ & $335(22.8 \%)$ & \\
\hline \multicolumn{4}{|l|}{ Sex, n (\%) } \\
\hline Male & $575(47.7 \%)$ & $645(43.8 \%)$ & \multirow{2}{*}{0.04} \\
\hline Female & $631(52.3 \%)$ & $828(56.2 \%)$ & \\
\hline BMI, mean (SD) & $28.0(4.6)$ & $29.2(5.1)$ & $<0.001$ \\
\hline \multicolumn{4}{|l|}{ BMI, n (\%) } \\
\hline$<25.0$ & $343(28.4 \%)$ & $320(21.7 \%)$ & \multirow{3}{*}{$<0.001$} \\
\hline$\geq 25.0$ and $<30.0$ & $489(40.6 \%)$ & $547(37.2 \%)$ & \\
\hline$\geq 30.0$ & $374(31.0 \%)$ & $605(41.1 \%)$ & \\
\hline \multicolumn{4}{|l|}{ Race, n (\%) } \\
\hline African-American & $140(11.6 \%)$ & $304(20.7 \%)$ & \multirow{4}{*}{$<0.001$} \\
\hline Caucasian & $1048(86.9 \%)$ & $1119(76.1 \%)$ & \\
\hline Asian & $6(0.5 \%)$ & $13(0.9 \%)$ & \\
\hline Other non-white & $12(1.0 \%)$ & $35(2.4 \%)$ & \\
\hline \multicolumn{4}{|l|}{ Any knee injury prior to study baseline, $\mathrm{n}(\%)$} \\
\hline Yes & $369(30.6 \%)$ & $483(33.3 \%)$ & \multirow{2}{*}{0.14} \\
\hline No & $837(69.4 \%)$ & $969(66.7 \%)$ & \\
\hline \multicolumn{4}{|l|}{ Any knee surgery prior to study baseline, $\mathrm{n}(\%)$} \\
\hline Yes & $163(13.5 \%)$ & $271(18.7 \%)$ & \multirow{2}{*}{0.004} \\
\hline No & $1043(86.5 \%)$ & $1181(81.3 \%)$ & \\
\hline $\begin{array}{l}\text { Sedentary activity (minutes), mean (SD) } \\
\text { minimum-maximum }\end{array}$ & $\begin{array}{l}601.5(86.4) \\
241.4-849.6\end{array}$ & $\begin{array}{l}594.1(90.5) \\
342.3-842.3\end{array}$ & 0.07 \\
\hline $\begin{array}{l}\text { Light activity (minutes), mean (SD) } \\
\text { minimum-maximum }\end{array}$ & $\begin{array}{l}283.8(74.7) \\
42.3-545.1\end{array}$ & $\begin{array}{l}277.0(84.0) \\
62.5-647.0\end{array}$ & 0.01 \\
\hline $\begin{array}{l}\text { MV activity (minutes), mean (SD) } \\
\text { minimum-maximum }\end{array}$ & $\begin{array}{l}20.0(20.0) \\
0.0-142.9\end{array}$ & $\begin{array}{l}14.8(17.3) \\
0.0-136.1\end{array}$ & $<0.001$ \\
\hline $\begin{array}{l}\text { Average daily wear time (hours), mean (SD) } \\
\text { minimum-maximum }\end{array}$ & $\begin{array}{l}14.9(1.3) \\
10.6-19.5\end{array}$ & $\begin{array}{c}14.6(1.5) \\
10.25-19.9\end{array}$ & $<0.001$ \\
\hline
\end{tabular}

\begin{tabular}{|l|c|c|c|}
\hline KNEE-LEVEL CHARACTERISTICS & $\begin{array}{c}\text { Included } \\
\mathbf{n = 1 9 7 8 ~ k n e e s}\end{array}$ & $\begin{array}{c}\text { Excluded } \\
\mathbf{n = 3 1 5 0} \text { knees }\end{array}$ & p-value \\
\hline Baseline WOMAC pain, mean (SD) & $1.4(2.5)$ & $2.1(3.1)$ & $<0.001$ \\
\hline Baseline KL Grade, n (\%) & & & \\
\hline 0 & $1122(57 \%)$ & $708(25 \%)$ & $<0.001$ \\
\hline
\end{tabular}

Arthritis Care Res (Hoboken). Author manuscript; available in PMC 2020 February 01. 


\begin{tabular}{|c|c|c|c|}
\hline KNEE-LEVEL CHARACTERISTICS & $\begin{array}{c}\text { Included } \\
\mathrm{n}=1978 \text { knees }\end{array}$ & $\begin{array}{c}\text { Excluded } \\
\mathrm{n}=3150 \text { knees }\end{array}$ & p-value \\
\hline 1 & $550(28 \%)$ & $329(12 \%)$ & \\
\hline 2 & $199(10 \%)$ & $1129(40 \%)$ & \\
\hline 3 & $107(5 \%)$ & $650(23 \%)$ & \\
\hline \multicolumn{4}{|l|}{ Baseline Alignment, n (\%) } \\
\hline Neutral & $873(49.3 \%)$ & $1209(43.5 \%)$ & \multirow{3}{*}{$<0.001$} \\
\hline Varus & $692(39.1 \%)$ & $1145(41.2 \%)$ & \\
\hline Valgus & $207(11.7 \%)$ & $424(15.3 \%)$ & \\
\hline \multicolumn{4}{|c|}{ Radiographic Progression, Baseline to 4-Year Follow-up } \\
\hline Full sample & $267(14 \%)$ & & \\
\hline Men & $102(11 \%)$ & - ${ }^{* *}$ & \\
\hline Women & $165(15 \%)$ & & \\
\hline
\end{tabular}

included vs. excluded

**

not included because $<20 \%$ of this sample had data to determine frequency of radiographic progression

The table shows characteristics of persons (top portion) and knees (bottom portion) eligible for our study, and included (column 1) and not included (column 2). The most common reasons for not being included were having < 4 valid days of physical activity monitoring or missing $48 \mathrm{~m}$ or both $72 \mathrm{~m}$ and $96 \mathrm{~m}$ radiographic outcome data (see Figure 1). 
Table 2.

Physical Activity at Baseline and Radiographic Worsening of Knee OA over the Subsequent 4 Years (Dependent Variable)

\begin{tabular}{|c|c|c|c|}
\hline PREDICTOR & MODEL 1* & MODEL 2 & MODEL 3 \\
\hline Age (per 5 years) & $1.11(1.03,1.20)$ & $1.13(1.03,1.23)$ & $1.15(1.05,1.26)$ \\
\hline Sex (female) & $1.44(1.09,1.92)$ & $1.37(1.01,1.88)$ & $1.40(1.02,1.93)$ \\
\hline BMI (per $\left.1 \mathrm{~kg} / \mathrm{m}^{2}\right)$ & $1.07(1.04,1.11)$ & $1.07(1.04,1.11)$ & $1.07(1.03,1.10)$ \\
\hline SEDENTARY/10 min & & $0.99(0.96,1.01)$ & $0.99(0.97,1.01)$ \\
\hline MODERATE-VIGOROUS/10 min & & $0.98(0.90,1.07)$ & $1.00(0.91,1.09)$ \\
\hline Wear time & & $1.10(0.95,1.27)$ & $1.10(0.95,1.28)$ \\
\hline Race & & & $0.68(0.41,1.11)$ \\
\hline Knee injury & & & $0.96(0.70,1.32)$ \\
\hline Knee surgery & & & $1.27(0.81,1.99)$ \\
\hline WOMAC Pain & & & $1.13(1.07,1.19)$ \\
\hline
\end{tabular}

The table shows findings from logistic regression models using GEE. Adjusted ORs for sedentary and moderate-vigorous activity are per 10-minute increment. Significant findings $(\mathrm{p}<.05)$ are shown bolded and italicized. 